\title{
A Contribuição do Colóquio Internacional de Epistemologia e Sociologia da Ciência ao Campo da Administração no Brasil
}

\author{
MAURícIO SERVA \\ Universidade Federal de Santa Catarina / Departamento de CIÊnCias da Administração, Florianópolis, SC - Brasil
}

\begin{abstract}
Resumo
O artigo identifica e produz uma análise da contribuição do Colóquio Internacional de Epistemologia e Sociologia da Ciência da Administração para o avanço do campo científico da administração no Brasil entre os anos de 2011 e 2013. Para tanto é traçado um panorama temático dos trabalhos e conferências especiais apresentados no evento naquele período. São identificadas cinco grandes tendências em termos de contribuição. A primeira é a confirmação da inclinação crítica da epistemologia da administração no interior desta ciência social aplicada, dando continuidade a uma opção já esboçada desde o início dessa epistemologia específica nos anos 1980. A segunda é o enriquecimento dessas abordagens de cunho crítico via renovação de suas bases, reafirmando o que se passa em outras ciências, isto é, nota-se o enfraquecimento da crítica que se fundamentava nas chamadas "grandes narrativas". A terceira tendência se expressa pela troca intensa de saberes com outras ciências e disciplinas, propiciando avanços para a administração e também para essas disciplinas. A quarta tendência observada é o interesse em aprofundar o debate sobre as raízes filosóficas, históricas e científicas do conhecimento produzido até então na administração. Tal tendência aporta à administração diversos estudos de natureza propositiva, nos quais seus autores não se limitam a criticar/denunciar a ciência já posta, mas vão além e se arriscam a propor novas formas de analisar, conceber e vivenciar os fenômenos ligados à gestão e às organizações. O quinto tipo de contribuição do colóquio vem sendo a apresentação de análises epistemológicas de conhecimentos produzidos em diversas áreas específicas da administração, tais como estratégia, finanças e marketing, diversificando o potencial da epistemologia da administração. $\mathrm{O}$ artigo também promove uma breve apresentação dos artigos publicados na edição especial exclusiva para trabaIhos discutidos no Colóquio de Internacional de Epistemologia em 2014.
\end{abstract}

Palavras-chave: Colóquio de epistemologia da administração. Colóquio de sociologia da ciência da administração. Contribuições ao avanço da administração.

\section{The Contribution of the International Colloquium on Epistemology and Sociology of Science to the Administration Field in Brazil}

\begin{abstract}
The article identifies and produces a contribution analysis of the International Colloquium on Epistemology and Sociology of Management Science to advance in the scientific area of administration in Brazil, between 2011 and 2013. Thus, there is a particular overview description of works and special lectures presented at the event, during the period mentioned above. Five major trends are identified regarding contribution. The first one is the confirmation of critical epistemology inclination of the administration within that applied social science, continuing an option already outlined from the beginning of that particular epistemology, in the 1980s. The second is the enrichment of these approaches of critic characteristic through their bases renewing, reaffirming what happens in other sciences, that is, it is possible to notice the criticism weakening based on the so-called "grand narratives". The third trend is expressed by the intense exchange of knowledge with other sciences and disciplines, encouraging advances for the administration and those subjects. The fourth trend is the interest in further discussion on philosophical, historical and scientific roots of knowledge produced so far in business administration. That trend brings several studies of prospective nature for administration, in which the authors are not limited to criticizing/denouncing the already positioned science, but go beyond and risk on proposing new ways to analyze, conceive and experience the phenomena connected with management and organizations. The fifth conference type of contribution is the presentation of epistemological analysis of knowledge produced in several specific areas of administration, such as strategy, finance and marketing, diversifying the potential of the administration epistemology. The research also promotes a brief presentation of articles published in the exclusive special edition of works discussed at the International Colloquium on Epistemology of 2014.
\end{abstract}

Keywords: Epistemology colloquium of administration. Sociology colloquium of administration science. Contributions to the advancement of business administration.

Artigo recebido em 15 de dezembro de 2015 e aceito para publicação em 02 de fevereiro de 2016.

DOI: http://dx.doi.org/10.1590/1679-395158437 


\section{La Contribución del Coloquio Internacional de Epistemología y Sociología de la Ciencia al Campo de la Administración en Brasil}

\section{Resumen}

El artículo identifica y produce un análisis de la contribución del Coloquio Internacional de Epistemología y Sociología de la Ciencia de la Administración para el avance del campo científico de la administración en Brasil, entre los años 2011 y 2013. Para eso, se describe un panorama temático de los trabajos y conferencias especiales presentadas en el evento del período mencionado. Se identifican cinco grandes tendencias en términos de contribución. La primera es la confirmación de la inclinación crítica de la epistemología de la administración en el interior de esta ciencia social aplicada, dando continuidad a una opción ya esbozada desde el inicio de esa epistemología específica, en la década de 1980. La segunda es el enriquecimiento de esos abordajes de carácter crítico a través de la renovación de sus bases, reafirmando lo que pasa en otras ciencias, o sea, se nota el debilitamiento de la crítica que se fundamentaba en las llamadas "grandes narrativas". La tercera tendencia se expresa por el cambio intenso de saberes con otras ciencias y disciplinas, propiciando los avances para la administración y también para esas disciplinas. La cuarta tendencia observada es el interés en profundizar el debate sobre las raíces filosóficas, históricas y científicas del conocimiento producido hasta entonces en la administración. Esa tendencia aporta diversos estudios de naturaleza propositiva para la administración, en los que sus autores no se limitan a criticar/denunciar la ciencia ya posicionada, sino que van más allá y se arriesgan a proponer nuevas formas de analizar, concebir y vivenciar los fenómenos conectados con la gestión y las organizaciones. El quinto tipo de contribución del coloquio es la presentación de análisis epistemológicos de conocimientos producidos en diversas áreas específicas de la administración, tales como estrategia, finanzas y marketing, diversificando el potencial de la epistemología de la administración. El artículo también promueve una breve presentación de los artículos publicados en la edición especial exclusiva para trabajos discutidos en el Coloquio Internacional de Epistemología del año 2014.

Palabras clave: Coloquio de epistemología de la administración. Coloquio de sociología de la ciencia de la administración. Contribuciones para el avance de la administración.

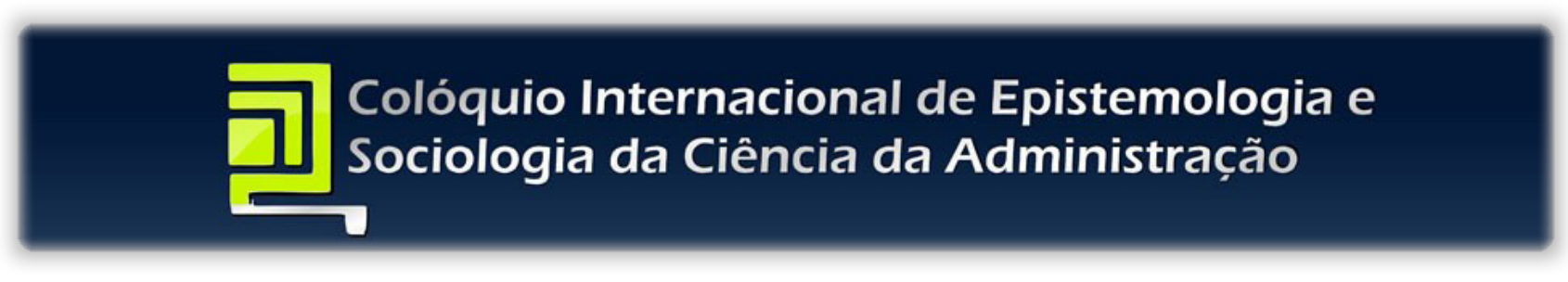

\section{INTRODUÇÃO}

É com imensa satisfação que participamos da segunda edição temática do periódico Cadernos EBAPE.BR inteiramente dedicada aos trabalhos apresentados no Colóquio Internacional de Epistemologia e Sociologia da Ciência da Administração. Neste número são publicados onze artigos entre aqueles debatidos no IV Colóquio, ocorrido em março de 2014. A satisfação é redobrada, pois, neste momento, já está sendo preparada uma terceira edição com os artigos apresentados no V Colóquio em 2015. Portanto, ao iniciar este manuscrito quero agradecer profundamente ao professor Fernando G. Tenório, editor-chefe do Cadernos EBAPE.BR, pelo convite para as edições especiais que concretizam um significativo apoio ao colóquio.

Como epistemologia específica (JAPIASSU, 1991; BERTHELOT, 2001), a epistemologia da administração vem se desenvolvendo significativamente no Brasil desde a década de 1990, de início com a adoção desse tema como disciplina em programas de pós-graduação de diversas escolas e, em seguida, com uma série de esforços feitos por pesquisadores situados em algumas organizações do campo científico.

Entre tais esforços, podemos citar alguns que julgamos os mais importantes. Em 2009, o tema Epistemologia e Administração foi criado na Associação Nacional de Pós-Graduação e Pesquisa em Administração (Anpad) pela Divisão de Ensino e Pesquisa em Administração e Contabilidade por iniciativa do professor Ariston Azevedo, sendo sucedido ao longo dos anos pelos professores Fabio Vizeu e Beatriz Villardi. Ainda na Anpad, a partir de 2010 o tema Ontologia, Epistemologias, Teorias e Metodologias nos Estudos Organizacionais é adotado pela Divisão de Estudos Organizacionais, então coordenada

*Fonte da imagem: Disponível em <http://coloquioepistemologia.com.br/>. Acesso em 18 fev. 2016. 
pelo professor Alexandre Carrieri; o primeiro líder (denominação estabelecida pela Anpad) desse tema foi o professor Maurício Serva, seguido pelos professores Sérgio Boeira e Marcelo Bispo. Em 2013, a Revista Gestão Organizacional (RGO) publicou uma edição especial intitulada Epistemologia e Métodos de Pesquisa em Administração e Contabilidade. A partir de 2011, a Universidade Federal de Santa Catarina (UFSC) realizou o Colóquio Internacional de Epistemologia e Sociologia da Ciência da Administração, por iniciativa do ORD - Núcleo de Pesquisa em Organizações, Racionalidade e Desenvolvimento. Desde 2013, o Cadernos EBAPE.BR vêm publicando edições temáticas exclusivamente com os artigos apresentados nesse colóquio.

Neste artigo me concentrarei no Colóquio de Epistemologia em razão dessa nova edição sobre o evento. Tentarei traçar um panorama temático dos trabalhos apresentados e das conferências principais proferidas de 2011 até 2013, complementando-o com uma breve apresentação dos artigos apresentados em 2014, veiculados nesta edição. Meu objetivo é oferecer ao leitor uma visão geral da contribuição que o referido evento vem dando ao campo científico da administração, ao congregar pesquisadores de todas as regiões de nosso país e também da França, de Portugal, do Chile, da Colômbia e dos Estados Unidos.

\section{O COLÓQUIO E SEUS TEMAS}

Único evento internacional de promoção regular (com periodicidade anual até 2015, quando passou a ser bienal) e de caráter específico para a epistemologia e a sociologia da ciência na área da administração, o colóquio organiza-se por temas, de acordo com os quais são submetidos os trabalhos e promovidas as sessões de apresentação e discussão. Optou-se, em sua realização, por manter um formato que privilegia o tempo para as discussões em detrimento do grande número de apresentações, entendendo seus organizadores que esta última é uma das razões da baixa qualidade de muitos eventos científicos na atualidade. Contudo, devido ao crescente interesse de pesquisadores em participar da iniciativa, acarretando assim um volume considerável de submissões de trabalhos a cada ano, o colóquio publicou em seu site (coloquioepistemologia.com.br) todos os trabalhos aprovados, independentemente de terem ou não espaço para apresentação oral durante o evento. Assim, os comentários expostos a seguir se referem ao conjunto dos trabaIhos publicados entre 2011 e 2013, que poderão ser consultados e obtidos na íntegra no referido site. Como mencionei acima, o periódico Cadernos EBAPE.BR já prepara uma nova edição com os artigos apresentados no colóquio de 2015; por conseguinte, espero abrir a nova edição com a continuidade do levantamento da contribuição do colóquio, quando enfocarei os trabalhos apresentados depois de 2013.

Os temas do colóquio são: análise epistemológica da administração; análise epistemológica de domínios específicos; racionalidade nas organizações; e sociologia da ciência da administração.

O primeiro tema - análise epistemológica da administração - congregou estudos sobre as bases epistemológicas das teorias de administração e das organizações; novas perspectivas sobre ideologia e ciência em administração; estágio atual e desdobramentos da epistemologia da administração; questões e tendências da administração como ciência social aplicada; possibilidades e limites da análise multiparadigmática; debate sobre a fragmentação da teoria das organizações; tendências e sofisticação do paradigma funcionalista; desafios ao paradigma crítico; e construção teórica e aplicabilidade na gestão.

No segundo tema privilegiou-se a análise epistemológica da produção científica em domínios conexos à administração, com ênfase em temas emergentes como: empreendimentos de economia social e solidária; relações entre sociedade civil, Estado e mercado; administração como ação coletiva; desenvolvimento territorial sustentável; e políticas públicas, entre outros.

O tema da racionalidade nas organizações procurou dar espaço às discussões sobre a racionalidade no avanço da epistemologia da administração; gestão e racionalidade: propostas de avanço do conhecimento; tensão entre racionalidades na prática da gestão; e decorrências da abordagem da racionalidade elaborada por Alberto Guerreiro Ramos.

Com o tema da sociologia da ciência, o colóquio se propôs também a se constituir um fórum de caráter reflexivo dos pesquisadores em administração, reunindo trabalhos sobre a abordagem desse campo científico do ponto de vista das 
suas instituições; interação entre os atores do campo da administração: poder, interesse, trocas simbólicas, estratégias e lógicas de ação dos atores do campo; condições sócio-históricas da elaboração e da divulgação da produção científica; e interface entre história da ciência e sociologia da ciência da administração.

Neste artigo optei por seguir tais temas, ressaltando em cada um as linhas mestras que vêm emergindo na produção científica apresentada. Dessa forma, penso poder identificar melhor as principais contribuições dadas pelo colóquio ao avanço do campo científico da administração.

\section{ANÁLISE EPISTEMOLÓGICA DA ADMINISTRAÇÃO}

Esse tema atraiu o maior número de trabalhos entre 2011 e 2013 e seis linhas mestras pareceram, em minha opinião, emergir com mais nitidez: 1) bases filosóficas e científicas da administração e do papel do administrador; 2) análise de áreas e temas da administração; 3) diálogos com outras disciplinas e as possibilidades de contribuição à administração; 4) obras de grandes autores e as possibilidades de contribuição à administração; 5) discussão paradigmática; e 6) formação e Ensino Superior.

A linha mestra que identifiquei como bases filosóficas e científicas da administração promoveu discussões sobre demarcação científica, tanto em administração quanto na perspectiva da ciência em geral. A construção da ciência da administração e seu desenvolvimento foram abordados de vários pontos de vista, incluindo: a démarche seguida ao longo do tempo; a crítica das teorias positivistas e normativas que predominam no campo; o debate sobre a importação da concepção e ciência e de seus métodos, denominado recentemente de "colonialismo versus decolonialismo". A fronteira entre epistemologia e metodologia foi alvo de destaque, ressaltando as possiblidades e os limites da pesquisa qualitativa. Podemos encontrar também aqui versões críticas sobre a concepção de empresa e sua interferência na construção do conhecimento, sobre o conceito de sustentabilidade empresarial, sobre a lacuna do tratamento das emoções na ciência da administração. Por outro lado, uma crítica às próprias abordagens críticas foi lançada via questionamento da ideia de emancipação veiculada por essas abordagens. Uma discussão filosófica sobre o papel do administrador foi iniciada por meio da ideia de "virtude epistêmica" desse profissional (AZEVEDO e GRAVE, 2011). Um dos trabalhos que mais ressaltaram o debate político no colóquio uniu o tratamento tanto da dimensão filosófica da teoria da administração quanto do papel do administrador: tendo como ponto de referência o conceito de "tipo burguês", o estudo aproximou o pensamento do filósofo Leandro Konder dos debates contemporâneos no entorno das teorias organizacionais, estendendo o questionamento ao posicionamento político dos quadros gerenciais (TENÓRIO, 2012).

A análise de áreas e temas da administração revelou uma diversidade que reflete em parte a variedade de dimensões específicas que compõe o campo. Trabalhos nas áreas de gestão internacional, administração pública, finanças, estratégia e abordagem contingencial, administração do desenvolvimento, gestão social e também a ecologia organizacional permitiram aprofundar o exame epistemológico da construção do conhecimento que é produzido. Em paralelo, temas como o controle, a competitividade, os sistemas de inovação (KARAM, 2011), a responsabilidade social corporativa, a organização familiar e o balance scorecard foram revisitados sob novos olhares, em geral adotando um prisma mais amplo e mais crítico que nos estudos tradicionalmente feitos.

Partindo de uma posição externa ao campo, esforços foram feitos para promover uma espécie de "diálogo" com outras disciplinas a fim de examinar as possibilidades de contribuição à ciência da administração. A filosofia abriu essa linha mestra, seguida pela teoria da ação comunicativa e a análise do discurso. Debates atuais tendo como base as teorias da tecnociência e do ator-rede ensejaram possibilidades de ampliação dos horizontes do conhecimento em administração. O diálogo com as teorias da complexidade apontou contribuições para a análise de redes organizacionais, para a teoria das organizações como um todo e para a estratégia. A dimensão moral da ciência produzida em administração recebeu uma proposta vinda da teoria da dádiva, originada na obra de Marcel Mauss e hoje muito discutida em economia e, em especial, em socioeconomia. Ainda integrando as tendências que se podem verificar na atualidade, o interesse pela dimensão prática da administração surgiu no evento por meio de trabalhos inspirados na teoria da atividade e em algumas teorias sobre práticas sociais (BULGACOV, OLIVEIRA e CANHADA, 2011). 
Um conjunto de estudos aportou ou reforçou as possibilidades de contribuição ao avanço da administração com base em obras de grandes autores, alguns já muito conhecidos dos pesquisadores da administração, outros talvez nem tanto. Assim, partes das obras de Max Weber, Michel Foucault, Jürgen Habermas, Edgar Morin e Jean-François Chanlat foram revisitadas, proporcionando novos olhares, ao passo que Norbert Elias e Bernard Lahire tiveram algumas de suas obras e conceitos vistos como prováveis contribuições.

O debate paradigmático continua em voga, constituindo uma linha mestra. O estudo de Gibson Burrel e Gareth Morgan ainda dá provas de sua fertilidade, com trabalhos abordando suas implicações e desdobramentos verificados ao longo do tempo. A constatação das disputas paradigmáticas no campo da administração foi levada ao colóquio tendo como base o conceito de Thomas Kuhn. Os paradigmas considerados críticos tiveram uma consideração especial pelo pleito de uma concepção de indivíduo mais conforme ao debate sobre emancipação (MOZZATO e GRZYBOVSKI, 2011). Também em determinadas áreas funcionais, como o marketing e a estratégia, a discussão paradigmática foi empreendida, na maioria dos casos, de uma perspectiva crítica.

A última linha mestra desse tema acabou por causar certa surpresa, pois não havia no início do colóquio uma expectativa sobre trabalhos com esse objetivo. Trata-se da formação e do Ensino Superior em administração. Ao refletir sobre o advento dessa linha mestra, infiro que pode ser uma das consequências do profundo questionamento pelo qual passa a administração. Os trabalhos apresentados expressam tal questionamento: reflexões críticas sobre a epistemologia da formação do administrador baseadas na dialética negativa (BUCCO e LOVISON, 2011), em Althusser e em bases humanistas. Numa visão mais voltada para certos sistemas institucionalizados de ensino, houve análises do ensino a distância e da avaliação do Ensino Superior no Brasil.

\section{ANÁLISE EPISTEMOLÓGICA DE DOMÍNIOS ESPECÍFICOS}

Com o intuito de ampliar o leque do exame epistemológico da produção científica, o colóquio ofereceu a oportunidade de divulgar e debater o que é produzido em determinados domínios conexos à administração sem que seus autores necessariamente assumissem o compromisso de estabelecer um diálogo mais preciso com a administração visando a seu avanço. Partimos da premissa de que é importante acompanhar aprofundada e criticamente o desenvolvimento dos domínios conexos, uma vez que estes guardam possibilidades sempre presentes de auxílio em projetos interdisciplinares dos quais pesquisadores em administração participam.

Os principais domínios conexos tratados foram iniciados no evento pelas teorias do desenvolvimento, objeto de estudo sempre discutido nos meios científicos da administração. As visões críticas de algumas das mais conhecidas correntes de interpretação do desenvolvimento foram então discutidas. A área de estudos da Tecnologia da Informação (TI) foi abordada pela lente do construtivismo e sua adequação a tais estudos. A contemporaneidade da discussão sobre a ética envolvendo a gestão e as organizações também foram alvos de debates; nesse contexto, chamou a atenção um estudo epistemológico sobre os fundamentos deontológicos do Código de Ética do Servidor Público em vigor no Brasil (PINTO, 2012). Nos campos mais relacionados às preocupações com os aspectos de políticas e ação sociais, o cooperativismo e seus estudos no Brasil (BOEIRA et al., 2012), bem como a economia social e solidária, o capital social e a questão das práticas sociais em face da moeda (CABRAL e MUZY, 2012) constituíram objetos de diversos trabalhos.

\section{RACIONALIDADE NAS ORGANIZAÇÕES}

Tal tema brinda e reconhece a importância e o avanço do campo de estudos sobre a racionalidade nas organizações em nosso país. O colóquio atraiu pesquisadores de várias regiões do Brasil interessados no desenvolvimento desse campo.

Uma comparação inusitada e bem-sucedida entre as obras de Guerreiro Ramos e Cornelius Castoriadis (NERY e PEIXOTO, 2011) foi apresentada no evento. $O$ estudo tomou como referência a crítica social empreendida por esses autores em face de dois polos: a racionalidade e o mercado. Outro trabalho ofereceu um balanço dos estudos contemporâneos que 
levam em consideração a perspectiva da racionalidade ambiental, destacando as tensões epistemológicas e metodológicas ocasionadas por tais estudos. Conflitos e tensões entre racionalidades no âmbito organizacional constituíram objetos de vários trabalhos, entre os quais podemos destacar estudos de caso sobre organizações do Terceiro Setor e também da chamada Economia de Comunhão. Um balanço da racionalidade e das bases epistemológicas dos processos de qualificação de gestores públicos permitiu o exame crítico de tais processos. Um enfoque específico do avanço da teoria das organizações buscou reunir em uma mesma elaboração as questões das identidades, das práticas discursivas e da racionalidade, visando a uma melhor compreensão do contexto organizacional.

\section{SOCIOLOGIA DA CIÊNCIA DA ADMINISTRAÇÃO}

Este último tema reflete o esforço desenvolvido há alguns anos pelo Núcleo de Pesquisa ORD com vistas a introduzir no Brasil a discussão sobre o campo científico da administração baseada na sociologia da ciência. Alguns trabalhos versaram sobre a análise do campo científico fundamentada no célebre conceito elaborado por Pierre Bourdieu. Em especial, um estudo teve como mote a advertência de que nem só de debates epistemológicos se compõe o nosso campo, mas também de embates em que o poder e os interesses influenciam a ação e os movimentos dos pesquisadores (BARBOSA, SANTOS, MATOS et al., 2013). Os participantes do evento ampliaram significativamente o raio dos debates sobre o campo e as condições de produção do conhecimento, a ponto de levantarem a intrigante questão de se a produção científica de qualidade estaria circunscrita às instituições do dito mundo acadêmico. $O$ aprofundamento do debate sobre as condições de produção que caracterizam o trabalho dos pesquisadores abriu espaços para a apresentação de trabalhos empíricos sobre o cotidiano desses profissionais, enfatizando as pressões às quais estão sujeitos, como empregam seu tempo (sua "agenda"), bem como sobre as implicações para aqueles que criam e dirigem grupos de pesquisa. Em particular, um estudo relacionou a atividade de gestão de grupos de pesquisa à gestão de organizações na atualidade, inspirado nos trabalhos de Henri Mintzberg (BINI, SERVA e MELO, 2013).

Sintetizadas as contribuições dos autores em cada tema nos três primeiros anos do colóquio, antes de fornecer um panorama desta edição elaborarei a seguir também uma síntese do conteúdo das conferências proferidas pelos pesquisadores convidados nos colóquios de 2011 a 2013.

\section{A CONTRIBUIÇÃO DOS CONFERENCISTAS CONVIDADOS}

Neste levantamento, eu não gostaria de omitir a contribuição dada pelos conferencistas convidados. Devido à importância do conteúdo de suas apresentações para a proposta do evento, apresentarei, ainda que sinteticamente, as principais mensagens expressas por pesquisadores de reconhecimento internacional que aceitaram dar sua parcela de contribuição para o avanço do nosso campo.

Nas três primeiras edições do colóquio entre os anos 2011 e 2013 se dirigiram a Florianópolis cinco conferencistas convidados, dois brasileiros e três estrangeiros: Pedro Demo, Hilton Japiassu, Laurent Thévenot, Romain Laufer e Bernard Paranque.

Pedro Demo e Hilton Japiassu, pesquisadores consagrados e, sem dúvida, os que até então melhor trabalharam a epistemologia no Brasil, propiciaram ao colóquio o acesso ao estado da arte nessa disciplina. Pedro Demo abordou o problema das novas vias de geração de conhecimento; essas vias demandariam uma nova visão da epistemologia? Assim, sua conferência teve como título "As novas epistemologias". O professor Demo expressou suas reflexões sobre as atuais ferramentas de TI, como a Wikipédia, fazendo um balanço dos aspectos e efeitos positivos e negativos desses instrumentos. Seria possível pensar em uma espécie de epistemologia para essas novas fontes de conhecimento? Eis uma das questões lançadas por Demo.

Hilton Japiassu tratou em sua conferência dos temas da interdisciplinaridade e mesmo da "transdisciplinaridade"; seriam, ambas, efetivamente concretizáveis no atual estado da arte da produção do conhecimento científico? O que poderia ser 
considerado mero discurso e, por outro lado, reais avanços em direção a tais práticas? Como poderia a epistemologia se posicionar diante desses desafios?

As questões tratadas por ambos os conferencistas brasileiros têm relação direta com uma ciência como a administração, cuja epistemologia específica está em construção e também pelo fato de ser uma ciência social aplicada, portanto estreitamente ligada aos fatos da época contemporânea.

Laurent Thévenot, diretor de estudos na prestigiosa École des Hautes Études en Sciences Sociales (Paris) e considerado um dos fundadores da sociologia pragmática, principalmente em razão do seu livro De la justification (BOLTANSKI e THÉVENOT, 1991), proferiu uma conferência intitulada "Avaliações e críticas das organizações compostas: entre os poderes devidos às convenções publicamente legítimas e as capacidades devidas aos engajamentos não públicos". Sua conferência partiu de duas preocupações: a primeira diz respeito à multiplicidade de paradigmas, isto é, como abordar as dimensões plurais no campo das organizações, suas racionalidades e lógicas de ação múltiplas, evitando a fragmentação da análise; e a segunda revela uma inquietação quanto à diversidade de ideologias em face do tratamento da dimensão política e da crítica. Vê-se claramente que as preocupações do professor Thévenot vão diretamente ao encontro dos temas abordados por diversos autores participantes do colóquio. O olhar de um dos autores mais destacados da sociologia pragmática francesa sobre esses temas aporta contribuições originais às discussões ocorridas em todas as edições do colóquio.

Romain Laufer, professor emérito da École des Hautes Études Commerciales de Paris, faz parte de um grupo de pesquisadores franceses que vem impulsionando vigorosamente a epistemologia da administração. Em 2000, o professor Laufer organizou uma das obras coletivas mais importantes dessa epistemologia específica, Les nouvelles fondations des sciences de gestion: éléments d'épistémologie de la recherche en management (ALBERT, HATCHUEL e LAUFER, 2012), livro que em 2013 ganhou uma nova edição, em inglês. Para o colóquio, o professor Laufer deu uma de suas contribuições mais significativas ao campo da administração: os processos de pesquisa abertos pela análise retórica em administração. Suas pesquisas refletidas em sua conferência estabelecem uma relação inovadora entre sofística, retórica e gestão.

Bernard Paranque é professor da Euromed Management, em Marselha, e titular da Chaire Finance Autrement, e abriu espaço no colóquio para a discussão da concepção da organização como ação coletiva, com base em um constructo sustentado nas abordagens de Elinor Olstrom, Luc Boltanski, Laurent Thévenot, Guerreiro Ramos, Hugh Willmott e Mats Alvesson. Na teoria organizacional, o tema da ação coletiva vem ganhando adesões de pesquisadores em diversos países nos últimos anos, enriquecendo o leque de possibilidades analíticas na fronteira entre a administração e a ciência política. O professor Paranque ofereceu aos participantes do colóquio uma versão teoricamente sofisticada da ação coletiva no âmbito das organizações, renovando o diálogo entre as duas ciências.

\section{PANORAMA DA EDIÇÃO TEMÁTICA}

Para esta edição foram aprovados onze artigos de acordo com os processos e as normas editoriais do Cadernos EBAPE.BR.

O primeiro artigo foi inserido no colóquio no tema análise epistemológica de domínios específicos e tem como título "International Development in the Brazilian Context in the 1950s and 1960s: A postcolonial reading of Guerreiro Ramos". Seus autores, Maria Cavalcanti e Rafael Alcadipani, empreendem uma leitura de parte da obra de Guerreiro Ramos relacionada à questão do colonialismo cultural e científico. O ponto de referência dos autores é a "teoria pós-colonial", o que lhes permitiu estabelecer alguns contrapontos à obra de Ramos. Uma breve, porém interessante, análise do contexto histórico da época em que os trabalhos de Ramos foram elaborados e a administração teve um incremento em sua institucionalização no Brasil conduz os autores a discutir a chamada abordagem International Business and Management Studies, bem como o conceito de desenvolvimento.

O segundo artigo é de autoria de Ana Paula Paes de Paula e é intitulado "Para além dos paradigmas nos estudos organizacionais: o ‘Círculo das Matrizes Epistemológicas'”. No colóquio foi apresentado o tema análise epistemológica da administração. Trata-se de um trabalho propositivo, em que a autora oferece aos leitores uma alternativa à lógica paradigmática tão empregada na análise organizacional. Com a proposta do "Círculo das Matrizes Epistemológicas" pretende-se partir de um questionamento aos trabalhos de Kuhn, Burrel e Morgan para incentivar os pesquisadores a afastarem-se 
da guerra paradigmática ensejada por esses trabalhos e, por conseguinte, a adotarem um posicionamento pautado na "teoria das reconstruções epistemológicas" como orientação para os estudos organizacionais. Podemos identificar aqui a intensidade do debate sobre os paradigmas, uma das linhas mestras desse tema comentada acima; nesse caso, o contraponto à formulação já tradicional dos paradigmas culmina em uma proposta alternativa promissora para a ciência da administração.

Em seguida temos o artigo "Independência ou norte: reflexões sobre a influência do estrangeirismo no campo do conhecimento da administração no Brasil”, de autoria de Lucas Juncklaus, Tiago Bini e Luis Moretto. Participando do tema análise epistemológica da administração, os autores se baseiam nas ideias contidas na abordagem da sociologia das ausências e das emergências elaborada por Boaventura Santos e, assim, identificam as ausências epistemológicas da teoria da administração em virtude da importação de teorias consideradas hegemônicas no campo da ciência da administração. Os autores pretendem inspirar os pesquisadores a seguir uma démarche interdisciplinar, adotando a ecologia dos saberes de Santos para superar as ausências epistemológicas identificadas. Vê-se a continuidade da linha mestra ligada à contribuição dos grandes autores (neste caso, Boaventura Santos) que identificamos em edições anteriores do colóquio.

Com o artigo "Da translação para o enactar: contribuições da teoria Ator-Rede para a abordagem processual das organizações", Patricia Camillis e Claudia Antonello reforçam no colóquio o emprego da teoria do Ator-Rede para fazer avançar a ciência da administração. Discutindo os conceitos de translação e enactment, as autoras procuram impulsionar a abordagem processual das organizações, trabalhando com as ideias de multiplicidade e fluidez na análise organizacional. O diálogo com a teoria do Ator-Rede vem marcando positivamente o colóquio, que se constitui, pela ação de seus participantes, um espaço de debate sobre a adoção dessa importante teoria em nosso campo.

Em seguida, o quinto artigo foi elaborado por Clovis Cerretto e Silvia Domenico, e também intensificou o diálogo com a teoria acima mencionada, se intitula "Mudança e teoria Ator-Rede: humanos e não humanos em controvérsias na implementação de um Centro de Serviços Compartilhados". O trabalho foi inserido no tema análise epistemológica da administração. O estudo enriqueceu significativamente o referido diálogo, pois é fruto de uma pesquisa empírica conduzida por mais de um ano em uma empresa prestadora de serviços públicos do estado de São Paulo, onde ocorria a implementação de um Centro de Serviços Compartilhados. A pesquisa empregou diversos métodos no campo, como observação participante, grupos de foco, entrevistas individuais, análise de documentos, recursos audiovisuais. Segundo os autores, as principais contribuições do estudo dizem respeito à problematização do controle em processos de mudança.

O sexto artigo segue a linha mestra das bases filosóficas e científicas no interior do tema análise epistemológica da administração. Seus autores, Everton Silva e Dimitri Toledo, apresentaram o estudo “As contribuições de Robert Cooper para o debate sobre ontologia organizacional". Defendendo a ideia de que a administração tem concepções teóricas ligadas à ciência moderna, os autores apresentam uma outra perspectiva ontológica próxima à concepção pós-moderna. A base principal são as contribuições de Robert Cooper, no sentido de que as "organizações sejam reconhecidas como acontecimentos inventivos múltiplos, que surpreendem o previsto e acentuam o caráter emergente da realidade social".

Paulo Cruz participa desta edição com um estudo cuja concepção, para além do conteúdo, é realmente inédita ao examinar as bases epistemológicas de estudos situados no limiar entre os campos da estratégia e da economia social. Compondo o tema dirigido aos domínios específicos, o estudo tem como título "Uma análise epistemológica da estratégia organizacional no âmbito da economia social". O autor empreendeu uma revisão de 74 trabalhos a partir do Canadá, no contexto de uma base de dados com mais de 3 mil estudos em economia social, perfazendo assim um exame refinado em um conjunto total de largo espectro. A contribuição tanto ao colóquio quanto ao campo da administração como um todo é também de largo espectro, já que alcança a epistemologia, a estratégia e a economia social.

O oitavo artigo situa-se fortemente na dimensão simbólica das organizações com uma proposta original: os sete pecados capitais como referência analítica. As autoras Marise Schadeck, Denize Grzybovski, Betina Beltrame e Anelise Mozzato apresentaram ao tema da análise epistemológica de domínios específicos o estudo "Cultura organizacional e sete pecados capitais: uma proposta para compreender os sistemas simbólicos" tendo como ponto de partida uma revisão teórica da metáfora na visão clássica aristotélica. O fundamento teórico estende-se a algumas concepções de Bourdieu e de Chanlat. Complementando a densidade do trabalho, um estudo de caso é relatado, testando a proposta analítica na dimensão empírica. 
Edson Quaresma ofereceu uma sofisticada abordagem ao campo da estratégia proveniente do realismo crítico. $\mathrm{O}$ artigo que tem como título "A realistic approach to strategic thinking and acting" convida os pesquisadores interessados na área da estratégia a considerarem a possibilidade de promover uma convergência entre sua área e o fundamento do realismo crítico, visando a colocar na mesma perspectiva analítica a prática, o praticante e a práxis. Trata-se de uma proposta por si mesma desafiadora, e cabe aos estudiosos desse domínio específico assumirem o debate e a experimentação que ela enseja.

Gustavo Matarazzo e Sérgio Boeira participam desta edição temática com o trabalho teórico-empírico "Incubação de cooperativas populares: representações sociais e tensões entre racionalidades". O trabalho foi inserido no colóquio no tema racionalidade nas organizações e aborda uma das questões mais atuais no âmbito dos estudos sobre a racionalidade no Brasil, isto é, a tensão entre modos de razão nas práticas cotidianas das organizações. O foco da análise empírica foi centrado no processo de incubação de cooperativas populares da Universidade de São Paulo (USP) e contou ainda com o recurso teórico da abordagem das representações sociais. Nessa configuração o estudo empregou uma conjunção teórica original que permitiu aos autores fazerem uma análise crítica e inovadora de uma dimensão da economia solidária: o processo de incubação tecnológica das cooperativas populares. Assim, um novo e múltiplo olhar é lançado a essa dimensão, muito estudada em nosso país, porém, nunca examinada do ponto de vista da tensão entre racionalidades e das representações sociais.

Fechando a edição temos um artigo que espelhou a amplitude da proposta do colóquio, pois se situa no domínio específico das finanças comportamentais. Kécia Galvão, Odilon Neto, Joséte Santos e Pierre Raboni apresentam o estudo "Análise dos modelos de precificação de ativos sob uma abordagem epistêmica do positivismo/pós-positivismo e do construtivismo", como fruto de uma análise epistemológica desses modelos atualmente muito em voga na construção do conhecimento em administração financeira.

\section{CONSIDERAÇÕES FINAIS}

No fim deste artigo espero, dentro das minhas limitações de conhecimento e de percepção, ter proporcionado uma visão geral das contribuições que o evento propicia ao avanço do campo científico da administração em nosso país.

Depois de cinco anos seguidos de realização, este balanço dos três primeiros anos do evento revela a resposta positiva que os colegas pesquisadores têm dado ao chamado que a organização do colóquio lançou ao campo desde 2011. Os quatro grandes temas, alguns com produção científica regular anterior ao evento, como a análise epistemológica da administração e racionalidade nas organizações, ao lado de um tema lançado pelo colóquio como o da sociologia da ciência da administração vem atraindo profissionais da pesquisa científica de todas as regiões do Brasil e também pesquisadores de diversos países. As linhas mestras que pude perceber como fruto da produção científica levada ao evento comportam trabalhos inovadores, ousados e que testemunham o vigor de pesquisadores mais experientes e conhecidos no campo, como também de outros mais jovens que têm no evento a chance de debater livremente, enriquecendo suas ideias e constructos.

Entre as várias tendências observadas, posso enfatizar a riqueza crescente das abordagens de cunho crítico, buscando novos caminhos com relação às antigas e de há muito desgastadas grandes narrativas que de antemão estabelecem suas "versões definitivas e inquestionáveis" do mundo e das realidades organizacionais, nas quais tudo o que importa já está dado a priori. A crítica renova-se pela sua autocrítica. A epistemologia da administração constrói-se e se reconstrói, redefinindo também as possibilidades, as razões e os efeitos do que poderíamos chamar de crítica; nesse sentido, reafirma-se também no evento a inclinação crítica dessa epistemologia que caracterizou sua produção científica desde o início, verificada na década de 1980.

Outra tendência digna de destaque no colóquio é o diálogo cada vez mais intenso com outras ciências e disciplinas, diálogo respeitoso para com estas, porém, não só aportando avanços para a administração, mas também para essas disciplinas. 
Posso indicar ainda mais como tendência e contribuição significativa o interesse em aprofundar o debate sobre as raízes filosóficas, históricas e científicas do conhecimento produzido até então em administração. A aceitação da crise pela qual passa também a ciência em um mundo mergulhado em crises sucessivas, uma vez que essa aceitação se estende à crise da ciência que fazemos sob o rótulo da administração (aí compreendida tanto a gestão como a teoria das organizações) amplia a necessidade do aprofundamento sem medo acerca da ciência que embasou nossa própria formação. 0 interesse nessa direção vem guiando esforços que se expressam em diversos estudos apresentados no colóquio. Um de seus mais importantes efeitos é o advento, no colóquio, de trabalhos propositivos, em que seus autores não se limitam a criticar/denunciar a ciência já posta, mas vão além e se arriscam a propor novas formas de analisar, conceber e vivenciar os fenômenos ligados à gestão, às organizações e, enfim, à administração. Esses pesquisadores se lançam a propor novas vias de se fazer ciência em nosso campo e em seus domínios específicos.

Por fim, eu gostaria de registrar uma interessante contribuição advinda do colóquio: estudos que ofereceram análises epistemológicas de conhecimentos produzidos em diversas áreas específicas da administração, como estratégia, finanças e marketing. Pesquisadores das várias áreas que compõem a administração demonstram a preocupação em examinar os fundamentos filosóficos e científicos dos conhecimentos que pautam suas respectivas áreas. Em suma, tais iniciativas são extremamente profícuas, pois a epistemologia da administração não pode ser restrita e exclusiva à apenas uma área, seja esta qual for. O evento tem como princípio abrir espaço para os trabalhos tendo em vista os quatro temas propostos e a qualidade dos trabalhos submetidos, sendo esses os critérios essenciais de seleção.

Pelos caminhos já percorridos nessas primeiras edições do colóquio, posso afirmar, em nome de sua Comissão Organizadora, que nos sentimos realizados em abrir espaços e criar as condições que proporcionam as contribuições dadas pelos colegas brasileiros e estrangeiros. Para tanto contamos com apoios fundamentais, como o que nos é dado por Cadernos EBAPE. BR. Portanto, encerro este artigo como o comecei: prestando o devido agradecimento ao valioso apoio recebido do professor Fernando G. Tenório, estendendo o agradecimento à Fabiana Braga Leal, Anderson Ricci e aos demais membros da equipe editorial do Cadernos EBAPE.BR. 


\section{REFERÊNCIAS}

ALBERT, D.; HATCHUEL, A.; LAUFER, R. (Org.) Les nouvelles fondations des sciences de gestion: éléments d'épistémologie de la recherche en management. Paris: Presse des Mines, 2012.

AZEVEDO, A.; GRAVE, P. S. A virtude epistêmica do administrador: primeiras explorações. In: I COLÓQUIO INTERNACIONAL DE EPISTEMOLOGIA E SOCIOLOGIA DA CIÊNCIA DA ADMINISTRAÇÃO, 2011, Florianópolis. Anais eletrônicos... Florianópolis: UFSC, 2011. Disponível em: <http://coloquioepistemologia.com.br/downloads_ category/2011/>. Acesso em: 28 jan. 2016.

BARBOSA, M. et al. Nem só de debates epistemológicos vive o pesquisador em administração: alguns apontamentos sobre disputas entre paradigmas e campo científico. In: III COLÓQUIO INTERNACIONAL DE EPISTEMOLOGIA E SOCIOLOGIA DA CIÊNCIA DA ADMINISTRAÇÃO, 2013, Florianópolis. Anais eletrônicos... Florianópolis: UFSC, 2013. Disponível em: < http://coloquioepistemologia.com.br/downloads_category/2013/>. Acesso em: 28 jan. 2016.

BERTHELOT, J. M. (Org.). Épistémologie des sciences sociales. Paris: PUF, 2001.

BINI, T.; SERVA, M.; MELO, D. As habilidades de gestão dos coordenadores de grupos de pesquisa no campo da administração. In: III COLÓQUIO INTERNACIONAL DE EPISTEMOLOGIA E SOCIOLOGIA DA CIÊNCIA DA ADMINISTRAÇÃO, 2013, Florianópolis. Anais eletrônicos... Florianópolis: UFSC, 2013. Disponível em: < http://coloquioepistemologia.com.br/downloads_category/2013/>. Acesso em: 28 jan. 2016.

BOEIRA, S. et al. Reflexão sobre aspectos teóricos e epistemológicos da produção nacional relativa ao cooperativismo. In: II COLÓQUIO INTERNACIONAL DE EPISTEMOLOGIA E SOCIOLOGIA DA CIÊNCIA DA ADMINISTRAÇÃO, 2012, Florianópolis. Anais eletrônicos... Florianópolis: UFSC, 2012. Disponível em: < http://coloquioepistemologia.com.br/downloads_category/2012/>. Acesso em: 28 jan. 2016.

BOLTANSKI, L.; THÉVENOT, L. De la justification: les économies de la grandeur. Paris: Gallimard, 1991.

BUCCO, L.; LOVISON, A. Reproblematizando a formação de administradores no Brasil: questões e tendências à luz da dialética negativa. I COLÓQUIO INTERNACIONAL DE EPISTEMOLOGIA E SOCIOLOGIA DA CIÊNCIA DA ADMINISTRAÇÃO, 2011, Florianópolis. Anais eletrônicos... Florianópolis: UFSC, 2011. Disponível em: <http://coloquioepistemologia.com.br/downloads_category/2011/>. Acesso em: 28 jan. 2016.

BULGACOV, Y.; OLIVEIRA, S.; CANHADA, D. Contribuição das "visões baseadas em práticas sociais" para a estratégia na disciplina da administração. In: I COLÓQUIO INTERNACIONAL DE EPISTEMOLOGIA E SOCIOLOGIA DA CIÊNCIA DA ADMINISTRAÇÃO,
2011, Florianópolis. Anais eletrônicos... Florianópolis: UFSC, 2011. Disponível em: <http://coloquioepistemologia.com.br/downloads_ category/2011/>. Acesso em: 28 jan. 2016.

CABRAL, E.; MUZY, P. Os valores e o valor da moeda: hipóteses sobre a comensurabilidade e a monetarização do impacto de projetos sociais. In: II COLÓQUIO INTERNACIONAL DE EPISTEMOLOGIA E SOCIOLOGIA DA CIÊNCIA DA ADMINISTRAÇÃO, 2012, Florianópolis. Anais eletrônicos... Florianópolis: UFSC, 2012. Disponível em: < http://coloquioepistemologia.com.br/downloads_category/2012/>. Acesso em: 28 jan. 2016.

JAPIASSU, H. Introdução ao pensamento epistemológico. Rio de Janeiro: Francisco Alves, 1991.

KARAM, C. A. Sistemas de inovações: uma análise epistemológica. In: I COLÓQUIO INTERNACIONAL DE EPISTEMOLOGIA E SOCIOLOGIA DA CIÊNCIA DA ADMINISTRAÇÃO, 2011, Florianópolis. Anais eletrônicos... Florianópolis: UFSC, 2011. Disponível em: <http://coloquioepistemologia.com.br/downloads_category/2011/>. Acesso em: 28 jan. 2016.

MOZZATO, A.; GRZYBOVSKI, D. Desenvolvimento paradigmático da teoria das organizações: uma abordagem crítica e a concepção de indivíduo na perspectiva emancipatória. In: I COLÓQUIO INTERNACIONAL DE EPISTEMOLOGIA E SOCIOLOGIA DA CIÊNCIA DA ADMINISTRAÇÃO, 2011, Florianópolis. Anais eletrônicos... Florianópolis: UFSC, 2011. Disponível em: <http://coloquioepistemologia.com.br/downloads_category/2011/>. Acesso em: 28 jan. 2016.

NERY, M.; PEIXOTO, D. Mercados e racionalidades sob a perspectiva de Alberto Guerreiro Ramos e Cornelius Castoriadis. In: I COLÓQUIO INTERNACIONAL DE EPISTEMOLOGIA E SOCIOLOGIA DA CIÊNCIA DA ADMINISTRAÇÃO, 2011, Florianópolis. Anais eletrônicos... Florianópolis: UFSC, 2011. Disponível em: <http://coloquioepistemologia.com.br/downloads_category/2011/>. Acesso em: 28 jan. 2016.

PINTO, R. S. Uma análise epistemológica do conteúdo das regras deontológicas do Código de Ética do Servidor Público Federal do Brasil. In: II COLÓQUIO INTERNACIONAL DE EPISTEMOLOGIA E SOCIOLOGIA DA CIÊNCIA DA ADMINISTRAÇÃO, 2012, Florianópolis. Anais eletrônicos... Florianópolis: UFSC, 2012. Disponível em: < http://coloquioepistemologia.com.br/downloads_category/2012/>. Acesso em: 28 jan. 2016.

TENÓRIO, F. O "tipo burguês" e o pensamento organizacional. In: II COLÓQUIO INTERNACIONAL DE EPISTEMOLOGIA E SOCIOLOGIA DA CIÊNCIA DA ADMINISTRAÇÃO, 2012, Florianópolis. Anais eletrônicos... Florianópolis: UFSC, 2012. Disponível em: < http://coloquioepistemologia.com.br/downloads_category/2012/>. Acesso em: 28 jan. 2016.

Maurício Serva

Doutor em Administração pela Escola de Administração de Empresas de São Paulo da Fundação Getulio Vargas (EAESP/FGV); Professor na Universidade Federal de Santa Catarina (UFSC); Coordenador do Colóquio Internacional de Epistemologia e Sociologia da Ciência da Administração e do Núcleo Organizações, Racionalidade e Desenvolvimento (www.redeord.com); Editor da revista Ciências em Debate. E-mail: mauserva@gmail.com 